\title{
Greenland ice cap aeromagnetic survey 1983: acquisition of high sensitivity total field and gradient magnetic data
}

\author{
L. Thorning, M. Bower, C. D. Hardwick and P. J. Hood
}

\section{Introduction}

A new high sensitivity aeromagnetic survey covering approximately $145000 \mathrm{~km}^{2}$ of the Inland Ice (fig. 14) has been carried out during two periods of field operations in April/May and September 1983. It is the first time a systematic, high sensitivity aeromagnetic coverage over the Greenland Inland Ice has been achieved. This note briefly reports on the background of the project, the field operations, and the preliminary results.

Previous aeromagnetic surveys of ice-free regions of central and southern West Greenland (Thorning, 1976, 1977, and in prep.) have shown that many major geological boundaries are clearly reflected in the aeromagnetic data acquired over these regions. Geological field work in south-east Greenland has revealed the existence of similar geological boundaries, but their assumed position under the Inland Ice has so far been guesswork. The aeromagnetic survey reported here is intended to provide real information on regional structures under the Inland Ice between the two coastal areas.

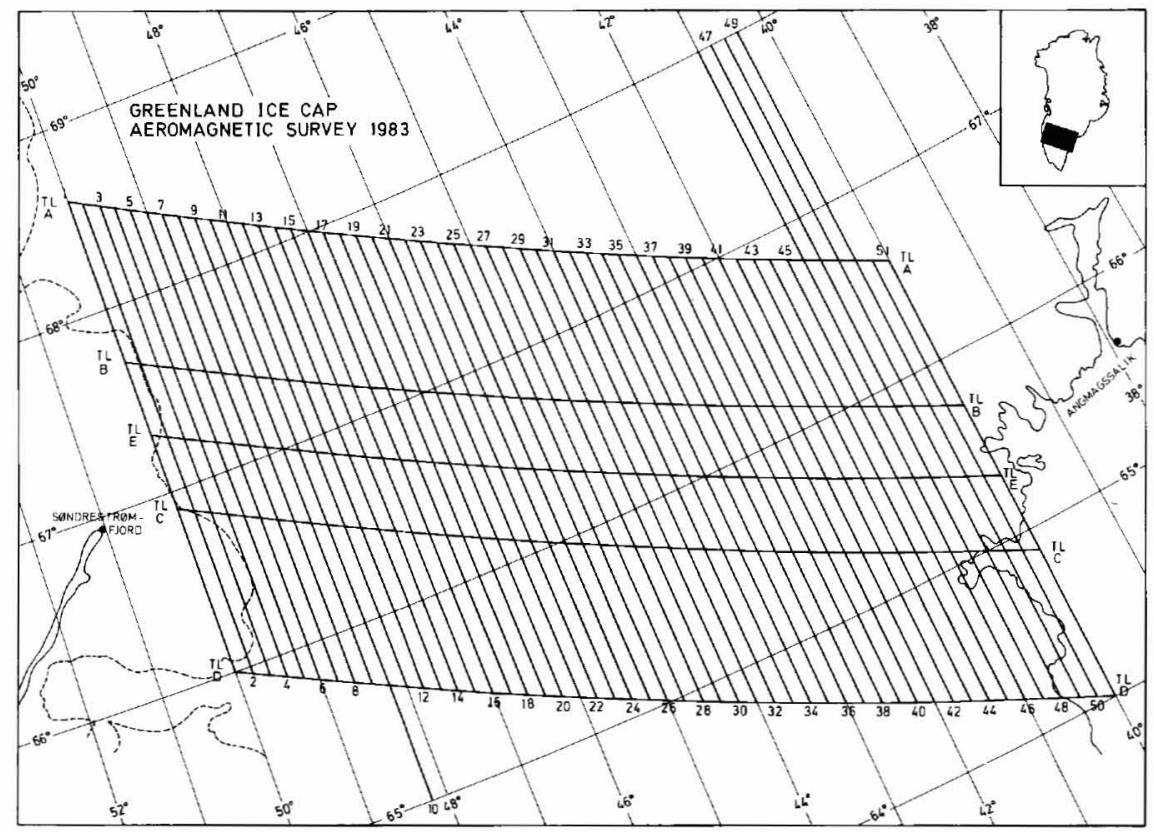

Fig. 14. Sketch map of the survey area showing all lines flown in 1983 within this area. In addition single tie lines not shown here (see text) were also flown. 


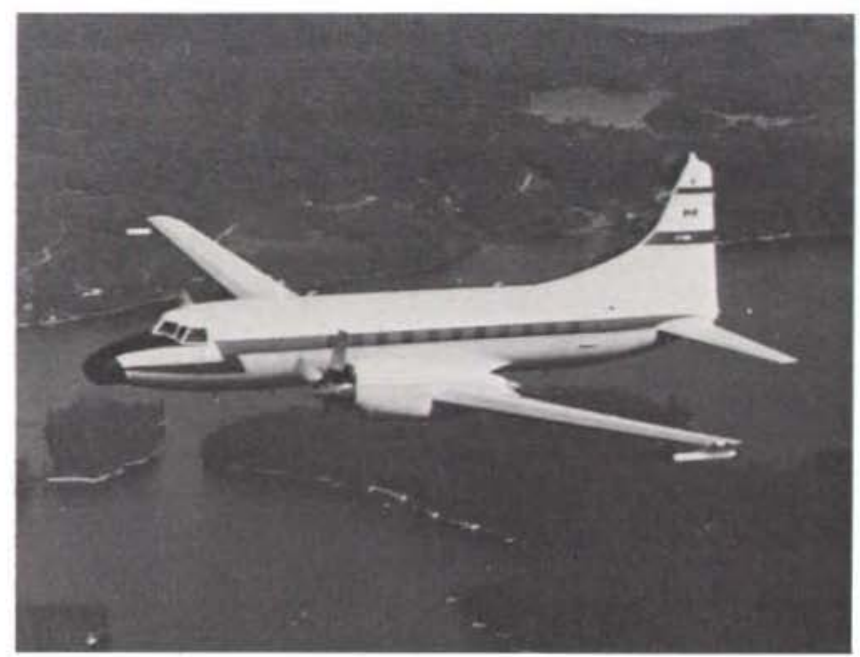

Fig. 15. The NAE Convair 580 in flight. Note the magnetometer sensors in the wing-tip and at the top of the tail.

The project is carried out jointly by the the Geological Survey of Greenland (GGU), the Geological Survey of Canada (GSC), and the National Aeronautical Establishment (NAE) of the National Research Council of Canada. It was known that such a survey would be a major challenge for any airborne system, and it is very satisfactory that the successful conclusion of the first part of the project, the airborne operation, can be reported.

\section{Aircraft and instrumentation}

The Canadian Convair 580 research aircraft (C-FNRC) (fig. 15) operated by NAE was used for the airborne operation. It is equipped with an advanced system for aeromagnetic surveying, largely developed by NAE (Hardwick, 1982). The aircraft carries a 3-axis magnetic gradiometer, a newly developed magnetic compensation system, a digital data acquisition system, and a number of navigational systems (inertial, VLF-Omega, Loran-C, Doppler, and video recording of flight path). The three optically pumped caesium magnetometers (strap-down version, VIW $2322 \mathrm{~A} 2$, now Scintrex), placed one at each wing tip and one in the tail, allow the recording of lateral, longitudinal, and vertical magnetic gradients as well as magnetic total field with a very high degree of accuracy.

Base station recording of diurnal geomagnetic variation was carried out at Søndre Strømfjord, and for the September operation also at the Dye 3 station on the Inland Ice. Geometrics proton precession magnetometers were used with digital data logging on a HewlettPackard HP85 computer or a Geometrics G724 data logger. The two base station systems worked in synchrony with the airborne system. For the May operation, magnetometer data from the ground station were transmitted to the aircraft via a high frequency data link for recording and for real time monitoring to ensure that the Earth's magnetic field was sufficiently quiet for surveying. 


\section{Survey operations}

The airborne operations were based at Søndre Strømfjord airport. Safety regulations and the range of the aircraft allowed 4 to 5 hours' flight time for each sortie. A total of $\mathbf{1 0 4 . 5}$ flight hours were used on 21 sorties. Approximately 18600 line $\mathrm{km}$ of aeromagnetic data were acquired in a regular net of $51 \mathrm{~N}-\mathrm{S}$ lines $9-11 \mathrm{~km}$ (12' of longitude) apart, and five tie lines (fig 14). Flight altitude was kept at a constant $1000 \mathrm{ft}$ over the surface of the ice cap, and over coastal areas at approximately $1000 \mathrm{ft}$ by drape flying. The flight line lay-out of fig. 14 is a compromise between the geological objective of the survey and the time and resources available. A general E-W geological trend was assumed and the $\mathrm{N}-\mathrm{S}$ lines placed to cover the region of the Inland Ice, where main geological structures were expected to occur.

Because of the limited time available in the field (a little over three weeks), it was not possible to adhere strictly to a specification for diurnal activity. No doubt there are cases, where diurnal noise has contaminated the airborne data, but the processing will probably be able to deal with that. Most days the diurnal conditions happened to be fair to good.

\section{Processing of data}

The processing of the data is at present taking place at NAE and GGU. The first step is a post-flight refly at NAE of all data, which is possible, because all primary navigational and magnetic data were stored on tape during flight. The purpose of the process is to optimize navigational accuracy and magnetic compensation, and the end result is the best possible data set obtainable from the recorded information. GGU will use the data to compile profile maps and contour maps using the facilities described in Thorning (1982). This will include magnetic adjustment and levelling using diurnal data and tie lines. The final decision on the use of the diurnal base station magnetometer data for correction of the survey data will, however, depend on results of an experiment on lateral propagation of diurnal variations, which will be carried out using the simultaneous recording of the diurnal geomagnetic field variations at Søndre Strømfjord and Dye3. Some preliminary interpretation of the aeromagnetic data will take place simultaneously with the processing of the data, and the interpretation will be finalized after the magnetic anomaly maps have been produced.

The processing described here will mainly be based on the total field data, although the gradient data will be treated at the same time. The availability of the gradient data opens up a number of interesting possibilities for improving the levelling of the data and the resolution of the contour maps which are to be produced. It will be approached from both a theoretical and a practical point of view.

\section{Results}

The initial inspection of the data shows these to be of excellent quality, and a great number of regional anomalies have been clearly defined by the survey. Line-to-line correlation is in most cases very convincing, and the geological features which are the sources of the total field magnetic anomalies can be followed over distances of up to $300-400 \mathrm{~km}$ before they leave the survey area. In the profile map, fig. 16, four total field profiles are shown. Because of the ice cap the distance to the magnetic sources varies from a few hundred metres at the edge of the Inland Ice to $2.5 \mathrm{~km}$ in the central part. The effect of this is visible in the 


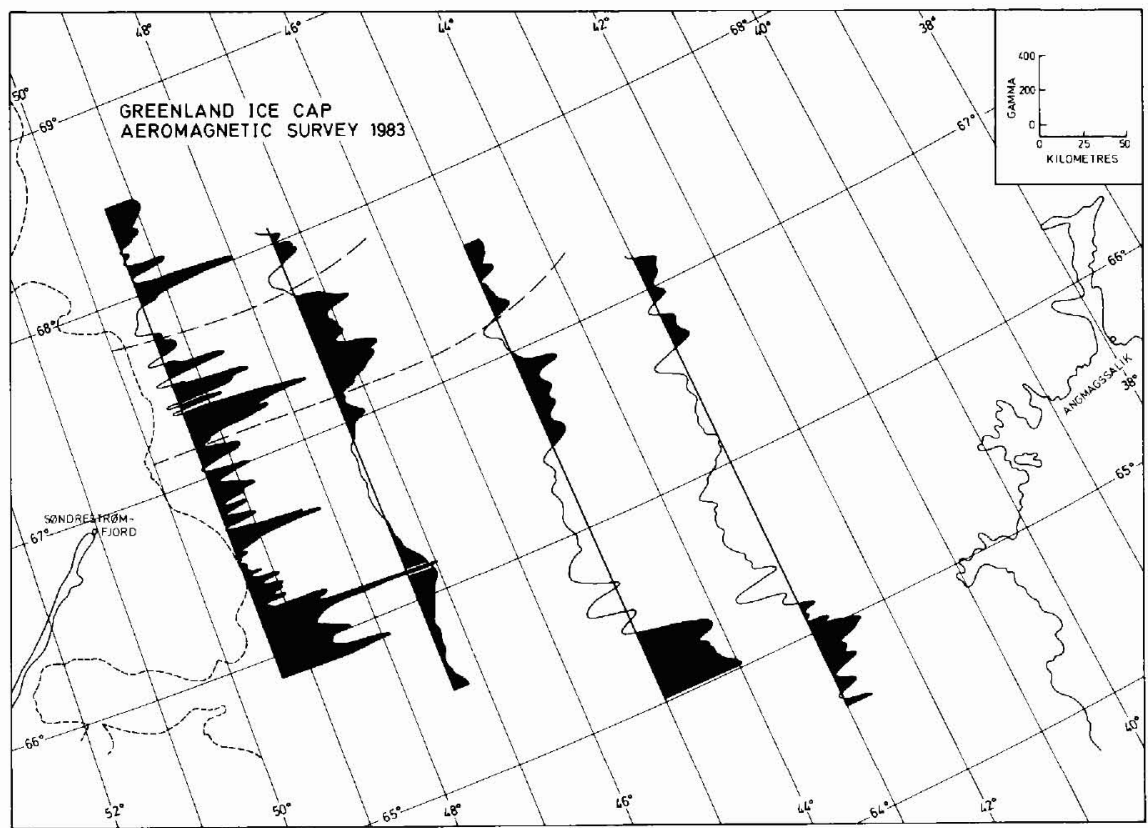

Fig. 16. Four profiles showing examples of anomalies. The broken line shows the approximate position of geological boundaries (see text) drawn on the basis of plotted preliminary total field profiles. The variations in frequency content of the profiles are caused by varying distance to magnetic sources.

data. The anomalies at the north and south end of the lines, and the magnetically smooth region of the central part of the lines are typical features which can be found, with local variations, on most $\mathrm{N}-\mathrm{S}$ profiles of the survey. The westernmost lines were flown over areas of central and southern West Greenland, which have been surveyed previously (Thorning, 1976, 1977), and as an example of the continuity of the data, the trend indicated on fig. 16 can be pointed out. This is probably the continuation of the band of highly magnetic rocks of the Isortoq complex north of Søndre Strømfjord discussed in Thorning (in prep.). Many other anomalies continuous over large distances can probably be correlated directly with known geological structures on the east or the west coast, but there are also anomalies to which no direct clues can be found in the coastal areas. All these features will of course be subjected to detailed interpretation, when the initial processing of the data has been concluded.

\section{Future work}

The excellent data acquired in 1983 have demonstrated beyond any doubt that it will be possible to gain new insight into the regional geological structure of Greenland by aeromagnetic surveying of the Inland Ice. It is the intention to continue survey operations if the necessary funding becomes available. Preliminary plans call for further surveying in 1984 over a part of the Inland Ice south of the area surveyed in 1983. 


\section{Additional tie lines}

In 1983 some additional tie lines were flown to assist the collection of regional magnetic data for a magnetic anomaly map of North America. One line was flown in the Davis Strait region (c. 2200 line $\mathrm{km}$ ), and the central tie line of the survey area over the Ice Cap was extended east to Iceland and west out into the Davis Strait (c. $1250 \mathrm{~km})$. These tie lines cross six to seven different survey areas.

The compilation of regional magnetic data into the Magnetic Anomaly Map of North America is progressing as a contribution to the Decade of the North American Geology Project.

Acknowledgements. The 'Greenland Ice Cap Aeromagnetic Survey' is a project in the tradition of many previous cooperative projects between GGU and GSC, this time also involving NAE. Costs so far have been shared between participating agencies. We would like to acknowledge the invaluable efforts of the NAE group: W. T. Chevrier (aircraft commander), S. Kereliuk, M. Morgan (pilots), G. Hoftyzer, T. Slack (project crew), M. Larsen, O. H. Stevens (maintenance crew chiefs), D. Blythe, B. McLeod, S. O'Connor (maintenance crew) and of E. Hansen, electronics technician, GGU. Finally, we would like to thank the USAF for asssistance with the Dye3 operations.

\section{References}

Hardwick, C. D. 1982: Benefits of NAE 3-axis magnetic gradiometer. The Northern Miner, August 19, 1982.

Thorning, L. 1976: Aeromagnetic surveys in southern and central West Greenland between $63^{\circ}$ and $71^{\circ}$ N. Rapp. Grønlands geol. Unders. 80, 61-65.

Thorning, L. 1977: Continuation of the aeromagnetic surveys in southern and central West Greenland between $64^{\circ}$ and $72^{\circ}$ N. Rapp. Grønlands geol. Unders. 85, 34-37.

Thorning, L. 1982: Processing and interpretation of aeromagnetic data in The Geological Survey of Greenland. Rapp. Grønlands geol. Unders. 114, 42 pp.

Thorning, L. (in prep): Aeromagnetic map of parts of southern and central West Greenland: acquisition, compilation and general analysis of data. Grønlands geol. Unders.

C.D.H.,

Flight Research Laboratory,

National Research Council,

Montreal Road,

Ottawa, Ontario,

KIA OR, Canada.

P.J.H.,

Regional Geophysics Subdivision,

Resource Geophysics and Geochemistry Div.,

Geological Survey of Canada,

601 Booth Street,

Ottawa, Ontario,

K1A OE8, Canada.
M.B.,

Flight Research Section, Bldg. U-61, National Research Council, Montreal Road, Ottawa, Ontario, K1A OR6, Canada. 